Portland State University

PDXScholar

\title{
Breaking Barriers to Bike Share: Insights on Equity from a Survey of Bike Share System Owners and Operators
}

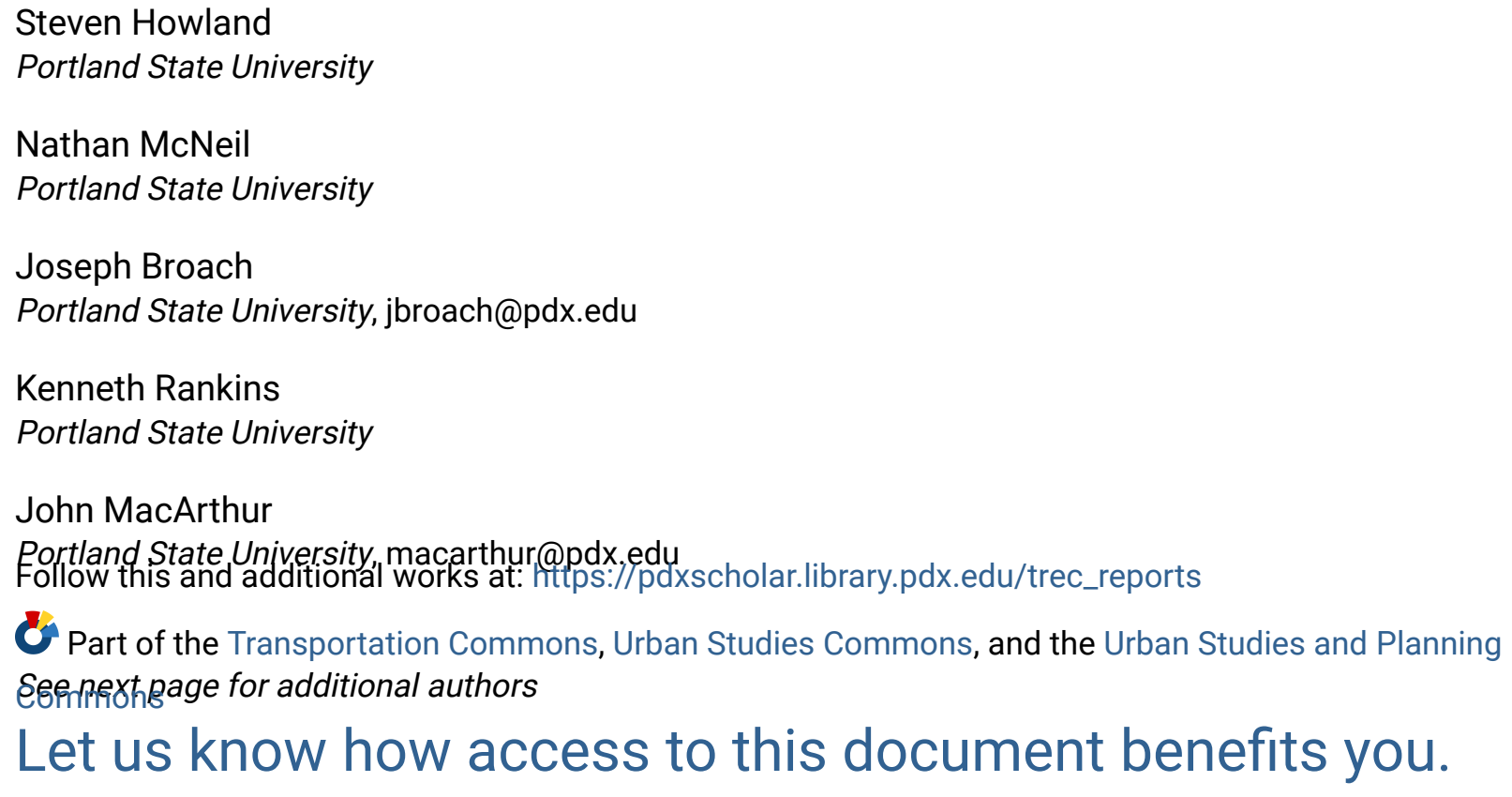

This Report is brought to you for free and open access. It has been accepted for inclusion in TREC Final Reports by an authorized administrator of PDXScholar. Please contact us if we can make this document more accessible: pdxscholar@pdx.edu. 


\section{Authors}

Steven Howland, Nathan McNeil, Joseph Broach, Kenneth Rankins, John MacArthur, and Jennifer Dill 


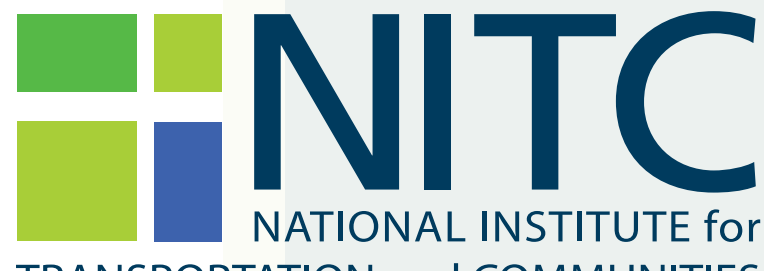

TRANSPORTATION and COMMUNITIES

\section{FINAL REPORT}

Breaking Barriers to Bike Share: Insights on Equity from a Survey of Bike Share System Owners and Operators

NITCN-RR-884a $\quad$ May 2017

NITC is a U.S. Department of Transportation national university transportation center.

HI!" TREC 



\section{BREAKING BARRIERS TO BIKE SHARE: INSIGHTS ON EQUITY FROM A SURVEY OF BIKE SHARE SYSTEM OWNERS AND OPERATORS}

Final Report

\section{NITC-RR-884a}

by

Steven Howland

Nathan McNeil

Joseph Broach

Kenneth Rankins

John MacArthur

Jennifer Dill

Portland State University

for

National Institute for Transportation and Communities (NITC)

P.O. Box 751

Portland, OR 97207
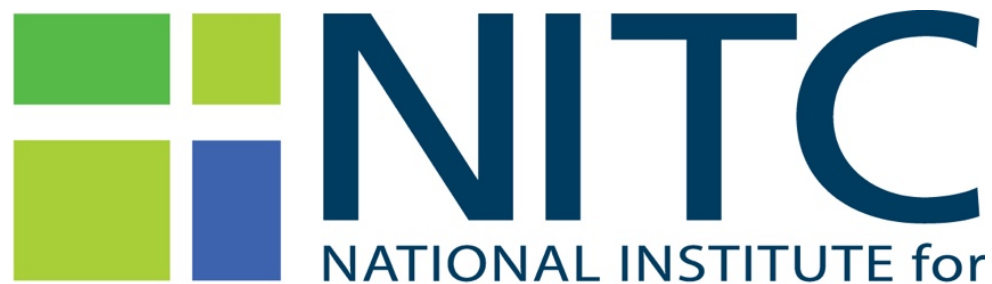

TRANSPORTATION and COMMUNITIES

May 2017 



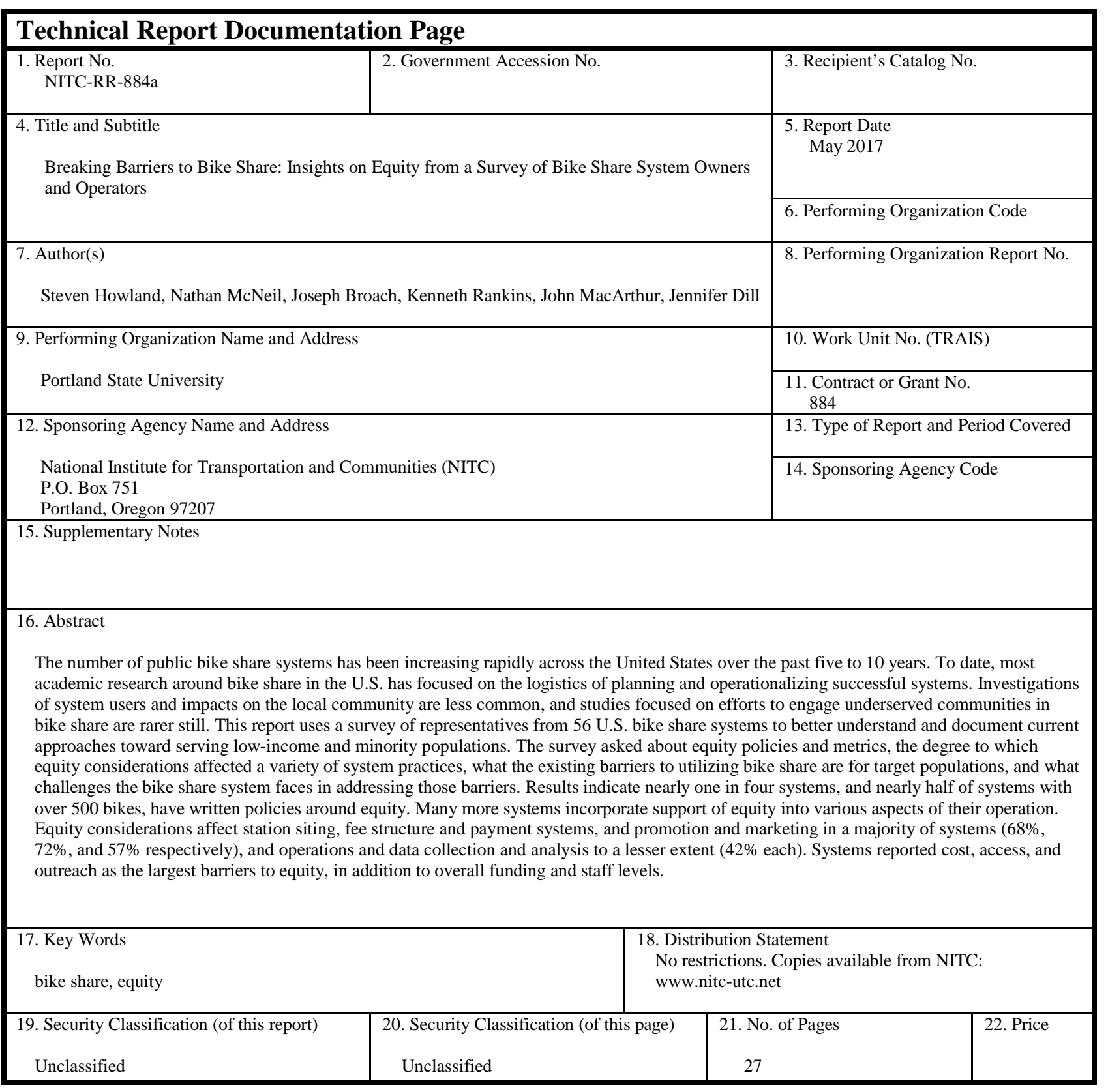




\section{ACKNOWLEDGEMENTS}

This research was funded by PeopleForBikes and the Better Bike Share Partnership (a collaboration among the City of Philadelphia, the Bicycle Coalition of Greater Philadelphia, the National Association of City Transportation Officials (NACTO), and PeopleForBikes, made possible by The JPB Foundation), and by the National Institute for Transportation and Communities (NITC) under grant number 884, a program of the Transportation Research and Education Center at Portland State University and a U.S. Department of Transportation university transportation center.

\section{DISCLAIMER}

The contents of this report reflect the views of the authors, who are solely responsible for the facts and the accuracy of the material and information presented herein. This document is disseminated under the sponsorship of the U.S. Department of Transportation University Transportation Centers Program in the interest of information exchange. The U.S. government assumes no liability for the contents or use thereof. The contents do not necessarily reflect the official views of the U.S. government. This report does not constitute a standard, specification, or regulation.

\section{RECOMMENDED CITATION}

Howland, Steven, Nathan McNeil, Joseph Broach, Kenneth Rankins, John MacArthur, and Jennifer Dill. Breaking Barriers to Bike Share: Insights on Equity from a Survey of Bike Share System Owners and Operators. NITC-RR-884a. Portland, OR: Transportation Research and Education Center (TREC), 2017. 


\section{CONTENTS}

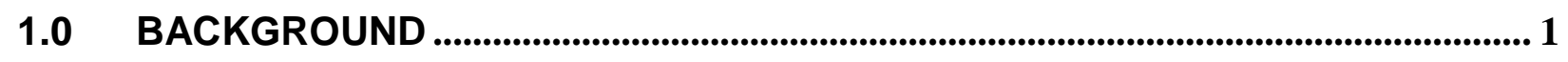

2.0 METHODOLOGY.................................................................................................. 3

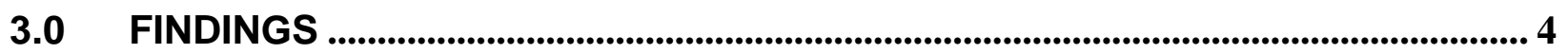

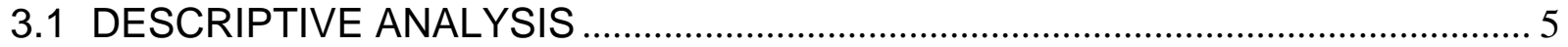

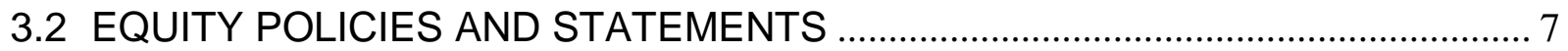

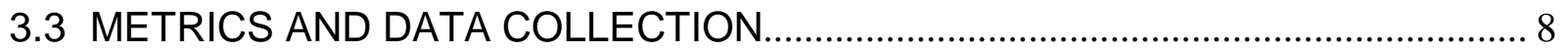

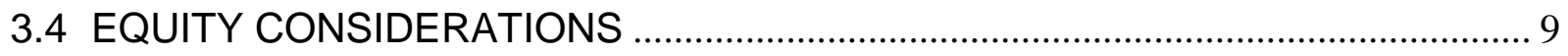

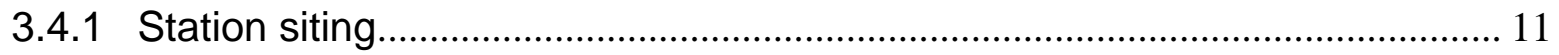

3.4.2 Fee Structure and Payment Systems ……………...................................... 12

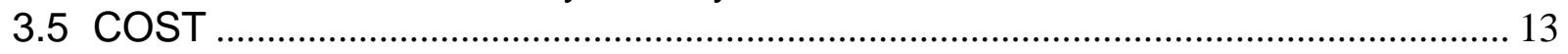

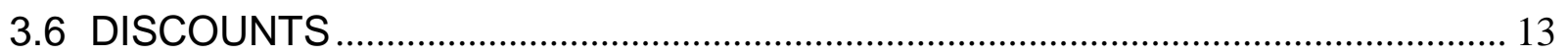

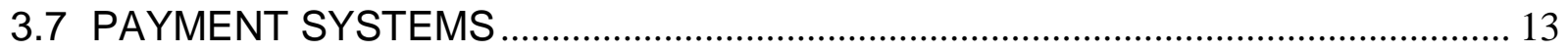

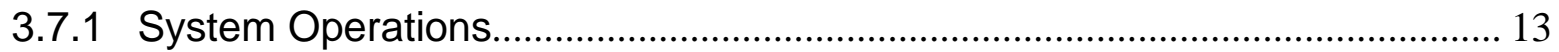

3.7.2 Promotion, Outreach, and Marketing ……………….......................................... 14

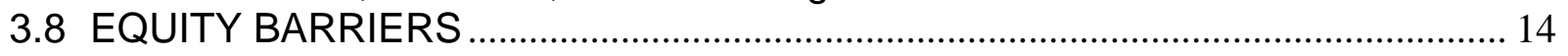

3.8.1 Perceived barriers for targeted equity users......................................................... 14

3.8.2 Barriers for the organization ......................................................................... 17

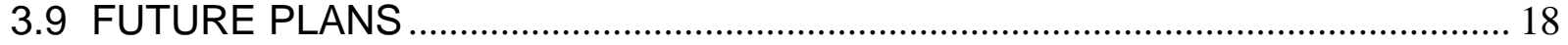

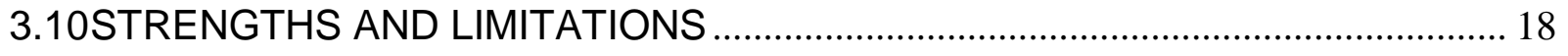

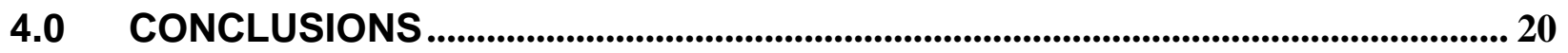

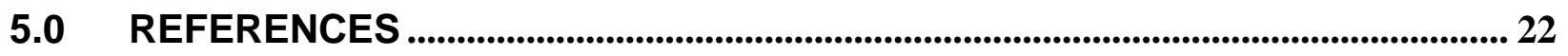




\subsection{BACKGROUND}

In 2015, there were over 800 bike share programs across the world, with approximately 1 million bicycles, a substantial increase from the handful that existed in the late 1990s (1). Because of this growth, research interest in public bike share systems has increased rapidly, with the number of new studies more than tripling from 31 during 2007-2010, to 98 during 2011-2014, and 122 in 2015-2016 alone (2). However, a search of the Transport Research International Documentation (TRID) database revealed relatively few bike share studies focused on equity or low-income populations (2). The majority of research to date has concentrated either on the logistics of designing and operating systems or else on broad transportation systems impacts. Investigations of system users and approaches to increase ridership among underserved communities have only just begun.

Despite the appeal and success of bike share in the U.S., there is growing evidence that certain groups are participating less and enjoying fewer benefits from these new transportation options. Research has shown that bike share users tend to have higher incomes (e.g. $1 ; 3 ; 4$ ), be more educated (e.g. $1 ; 5 ; 6)$, and be more often white $(5 ; 6)$ than the general population. For example, surveys of users of the Washington, D.C., Capital Bikeshare found that members had higher education levels and were more likely to identify as Caucasian than the city population as a whole; participation was extremely low among African American residents, whether looking at members or at occasional users (6).

Bike share has the potential to benefit disadvantaged communities if service could better match their needs. In London, a study found that residents in poorer areas would use bike share if stations were sited locally and prices were affordable relative to other modes (7). Bike share can serve as an important link to transit and to work: A survey of annual members in Boston found that trips to or from work were the most common trip purpose (8). Bike share systems have also been identified by underserved groups in Philadelphia as a potentially lower-cost, more-reliable substitute for transit (9). Bicycle ownership costs and lack of secure bike storage at home (problems that bike share systems can solve) were both identified as important barriers to cycling among specific low-income and minority populations in Portland, Oregon (10).

Station siting is an important factor in participation and access to bike share. Smith et al. found only four of the larger bike share systems locate over 40 percent of stations in communities categorized as having high economic hardship (11). Ursaki \& Aultman-Hall found that there is an inequitable distribution of bike share access in seven cities, with significant differences in access based on race, education and income variables among the population groups (12). Research outside the U.S. has also found lower bike share station density in less-affluent neighborhoods (13). Further, models of bike share use in three U.S. systems revealed lower expected use when stations were located in neighborhoods with lower incomes and higher shares of people of color residents (14). 
Station siting is not the only factor affecting use by lower-income and diverse populations. One early study found that siting stations in low-income communities in Minneapolis yielded limited ridership, likely due to a lack of ongoing community engagement (15). Credit card requirements and equipment liability absent credit holds are another barrier to use by low-income and minority populations (16). A recent set of case studies discussing several American cities' attempts to connect low-income individuals to bike share found some successes via subsidized memberships to overcome cost barriers. However, difficulties persisted due to station siting and low use of stations in diverse communities (17).

The operating model for a bike share system may also influence equity outcomes. Throughout the U.S. there are a variety of operation models: nonprofit; privately owned and operated; publicly owned and operated; public owned/contractor operated; and vendor operated (8). For example, Divvy is a bicycle sharing system in the city of Chicago operated by the privately held company Motivate for the Chicago Department of Transportation. Meanwhile, Denver B-cycle is owned and operated by Denver Bike Sharing, a 501(c)3 nonprofit. The reliance on private funding for capital and operating costs may influence station siting and other operating decisions, with varying implications for equity outcomes. For instance, the profit motive in private funding may foreclose the possibility of locating stations in what may be low-use areas but would help reach targeted equity populations.

Efforts are underway to address these issues. In a survey of North American bike share operators, $35 \%(n=20)$ of respondents located stations based on equity reasons, 35\% subsidized membership, and 25\% assisted low-income members with payment options (18). Another study found that $43 \%(n=23)$ of surveyed bike share programs factored equity considerations into bike share station siting decisions (8). The Better Bike Share Partnership (BBSP), a multiorganizational collaboration funded by The JPB Foundation, aims to build equitable and replicable bike share systems. At the time of writing, BBSP had funded 15 bike share operators, cities and local nonprofits to help U.S. cities develop and implement strategies to increase bike share use in their own underserved communities.

This paper presents findings from a survey of bike share system owners and operators aimed at understanding how they are approaching service to underserved, low-income and minority communities. The research provides a snapshot of the extent of current efforts to address equity and reveals opportunities and challenges for improvement. Additional research is necessary to fully understand the impact of these efforts.

\section{EQUITY}

Inequity in the U.S. has its roots in how the U.S. was formed due to the differential treatment of particular population groups. African-Americans were considered less than a whole person in population counts until ratification of the $14^{\text {th }}$ Amendment in 1868, and women were not granted the right to vote until 1920, to name just a few. Large steps were taken with the Civil Rights Acts in the 1960s, which made it a federal crime to discriminate against someone based on their race, color, sex, religion, or national origin in employment and housing. This has been expanded to include older adults and people with disabilities. In some areas of daily life in some states, antidiscrimination laws also apply to sexual orientation. 
It is the Civil Rights Act of 1964 that required transportation agencies receiving federal funds to abide by the anti-discrimination requirements of the act under Title VI of the act. Presidential executive orders have furthered the Title VI requirements to include environmental justice for minority and low-income populations and to accommodate populations with limited English proficiency.

As such, equity can apply to a wide variety of populations. Transportation agencies have a duty to ensure their programs accommodate all populations and evaluate their projects on the basis that they are not discriminating against protected populations. However, it is also important to recognize that not all projects will affect people differentially based on their protected classification. For instance, it is unlikely that adding a new transit line will adversely affect someone based on their religion. Regardless, all projects must be evaluated with a good-faith effort to ensure that not only are all possible adverse consequences identified but also ensure no group is benefiting more from a project than another. Considering the wide-ranging groups of people covered by equity, it is difficult for us to evaluate all potential adverse impacts of bike share. As such, we have focused our efforts in this study to evaluate bike share projects on equity terms for low-income and racial minority populations, who have been identified as the largest potential populations affected by the implementation of a bike share program. Where we find information pertaining to other protected classes, we have provided additional analysis for those groups.

\subsection{METHODOLOGY}

Using the Pedestrian and Bicycling Information Center's list of bike share programs (19), web searches, and help from the National Association of City Transportation Officials (NACTO), we identified 75 U.S. bike share systems that were either operational or in pre-launch. Our focus was on public bike share systems intended to serve a wide range of residents, although we did include a handful of larger university systems. We excluded systems with fewer than 40 bikes.

For each of the 75 systems, we sought to identify a key contact who could speak to overarching initiatives involving the system and any efforts to serve potentially underserved populations. In some cases, the identified contact was a representative of the public agency that owns, operates or oversees the bike share system, or some combination of the three. In other cases, the contact was a representative of a private vendor charged with managing the system. In the introductory email to each contact, we explained that we had identified them as a representative of the bike share system, and wanted the respondent to be someone who could speak about "decisions about system operations, policies and programs." We asked the recipient to inform us if someone else within the bike share system would be better suited to answer the survey. The initial request was emailed in March 2016. Up to three additional reminders were sent to each of the cities that had not yet completed the survey.

Respondents were provided with several example definitions of equity from organizations working in the bicycle realm. These included: 
- League of American Bicyclists: "the guarantee of fair treatment, access, opportunity, and advancement for all, while at the same time striving to identify and eliminate barriers that have prevented the full participation of some group" and

- Advocacy Advance: "recognizing and reacting to the under-representation of youth, women, and people of color in advocacy efforts and local transportation decisions."

We noted that some would add low-income and older adults or further recognize the ramifications of past inequity along with ongoing inequity. Our instructions also informed respondents that they were not limited to these definitions.

The survey started by gathering basic information about the bike share system, including the role of the respondent's organization in the system, type of organization, operational status of the system, and the number of bikes in the system. We then asked if the bike share system had an equity statement or policy (and, if so, to provide the text), and if it had established specific metrics to measure equity in the system (and, if so, what those metrics are). The next section asked what role, if any, equity considerations played in several key bike share system operational areas, including station siting; fee structure and payment systems; system operations, including employment; promotion, outreach and marketing; and data collection, including assessment of user (and potential user) demographics. For each area, we also asked them to explain how equity was incorporated.

Where we asked respondents to identify how deeply equity influenced that part of their system, we used ANOVA to test group differences. A majority of the analysis focused around the openended responses that allowed system respondents to explain how equity was considered in each section. We used an inductive coding scheme to identify key words or themes. Over 200 codes were identified in the analysis of the open-ended questions, many of which were combined in some way in explaining the findings.

As with any survey, there are limitations with respect to sampling and response rates. Although we attempted to identify all current or planned bike share systems, we were not able to identify appropriate contacts for some systems. We learned of other systems after completing the survey. It is difficult to assess the potential response bias for this survey without a complete and accurate inventory of systems. We did find very little difference between the systems responding and not responding in terms of Census measures of city size, people of color population numbers, and poverty rates. Another limitation of the survey is having a single person respond. While we made attempts to identify the most knowledgeable person to respond, as noted in some of our findings, a single person is not always aware of all aspects of the system.

\subsection{FINDINGS}

In our analysis, we first looked at the closed-ended questions on whether the respondent said they had equity policies or metrics and how they rated the role of equity in each of the different areas of their bike share operations. We then analyzed the responses we received in the open- 
ended questions where we asked the respondent to describe their equity policies, metrics, and the role of equity in areas of their bike share operations. Considering not every respondent answered the open-ended questions and those that did may not have given us the most detailed answers they could have, we focused the analysis more on what was present rather than what was absent. Terms such as low-income, diversity, underserved and disadvantaged communities were the respondents' terms and often were not well defined. In exploring equity implications, it is important to recognize the differences between strategies that target low-income users and those that target specific racial/ethnic groups as the two groups are not the same nor mutually exclusive.

\subsection{DESCRIPTIVE ANALYSIS}

Fifty-six of the 75 systems (75\%) completed the survey, while three provided a partial response. One system refused. Our analysis included only those that completed the survey. Table 1 shows how respondents classified their organizations. Respondents to the survey were generally evenly split among owner (30\%), operator (27\%), and owner and operator (30\%). Most respondents represented either a government agency or nonprofit organization. Four of the systems selfidentified as universities, which we excluded from analysis outside of what is presented in Table 1 as the equity dimensions on college campuses seemed likely to differ from city systems. Most of the systems that responded were already operational (82\%). Just over half of the systems we considered medium-sized (100-500 bikes), while around a quarter were small systems ( $<100$ bikes) and a quarter were large systems ( $>500$ bikes). In terms of geographic spread, around a third of responding organizations were from the West U.S. Census region, just over half were split between the South and Midwest regions, and only 13\% were located in the East region. 
Table 1 Responding Organization and Bike Share System Characteristics

Percentage of Responding

Organizations

\begin{tabular}{ll}
\hline Responding Organization role in Bike Share system & \\
\hline Owner & $30 \%$ \\
\hline Operator & $27 \%$ \\
\hline Owner and Operator & $30 \%$ \\
\hline Partner - Not owner or operator & $13 \%$ \\
\hline$n$ & 56 \\
\hline Responding Organization Type & \\
\hline Government & $48 \%$ \\
\hline Nonprofit organization & $41 \%$ \\
\hline Private Operator & $6 \%$ \\
\hline University & $5 \%$ \\
\hline$n$ & 56 \\
\hline Launch Status & \\
\hline Operational & $82 \%$ \\
\hline Pre-launch & $18 \%$ \\
\hline$n$ & 56 \\
\hline Number of Bikes in System & \\
\hline Up to 100 bikes (small) & $25 \%$ \\
\hline 101 to 500 bikes (medium) & $52 \%$ \\
\hline 501 or more bikes (large) & $23 \%$ \\
\hline$n$ & 56 \\
\hline U.S. Census Region & \\
\hline Northeast & $13 \%$ \\
\hline South & $25 \%$ \\
\hline Midwest & $29 \%$ \\
\hline West & $34 \%$ \\
\hline$n$ & 56 \\
\hline
\end{tabular}




\subsection{EQUITY POLICIES AND STATEMENTS}

Only 23\% of respondents reported that their systems had some form of equity statement (Table 2 and Figure 1). Large bike share systems were most likely to have an equity statement, with nearly half of such systems saying so. Systems that have equity statements had a median percentage of people of color populations in their cities 21 percentage points higher than those without equity statements. "Other" respondents almost unanimously stated their equity policies were in development.

Table 2 Presence of Equity Policy and Metrics, by System Size

\begin{tabular}{|c|c|c|c|c|}
\hline Equity Policies & Up to 100 & 101 to 500 & $\begin{array}{c}501 \text { or } \\
\text { more }\end{array}$ & All \\
\hline Have Equity statement or policy & $18 \%$ & $14 \%$ & $46 \%$ & $23 \%$ \\
\hline Do Not & $73 \%$ & $69 \%$ & $39 \%$ & $62 \%$ \\
\hline Other & $9 \%$ & $17 \%$ & $15 \%$ & $15 \%$ \\
\hline Total & 11 & 29 & 13 & 53 \\
\hline Equity Metrics & Up to 100 & 101 to 500 & $\begin{array}{c}501 \text { or } \\
\text { more }\end{array}$ & All \\
\hline Have Equity metrics & $9 \%$ & $17 \%$ & $46 \%$ & $23 \%$ \\
\hline Do Not & $82 \%$ & $69 \%$ & $46 \%$ & $66 \%$ \\
\hline Other & $9 \%$ & $14 \%$ & $8 \%$ & $11 \%$ \\
\hline Total & 11 & 29 & 13 & 53 \\
\hline
\end{tabular}

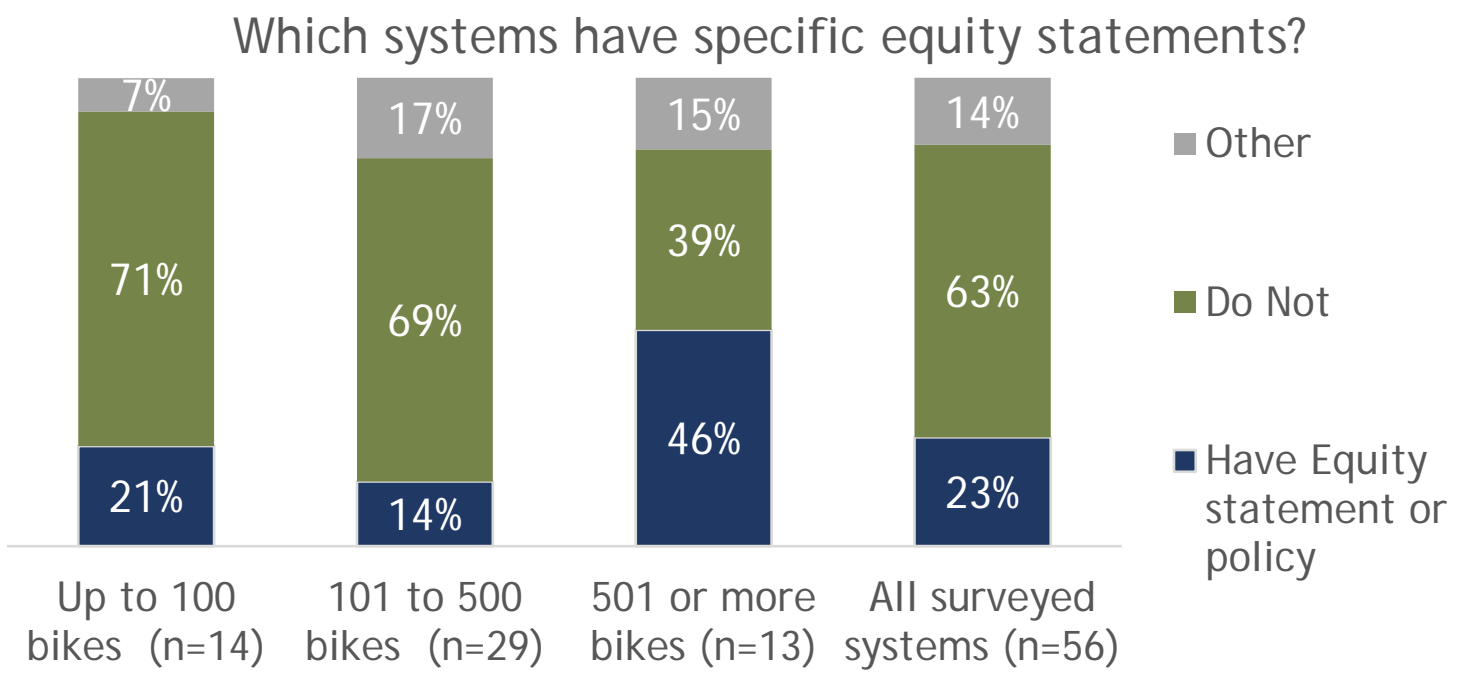

Figure 1 Percentage of bike share systems with equity statements, by system size

Whether systems were already operational and looking at expanding, planning their system, or any stage in between, there was a wide variance in how they approach equity. Many system respondents who said they did not have an equity statement or policy were in the process of drafting one. Three systems provided extensive statements or policies, which became even more 
extensive as they answered more specific items in the survey. Extensive policies typically outlined whom they were targeting with their equity goals, how, and to what end. Their statements were specific, rather than using general language.

Several systems had brief statements employing general language such as "providing accessible and affordable bicycles for all” or some variation thereof, or pointed to Title VI requirements. However, a reliance on Title VI may be inadequate in addressing equity concerns (20). This is primarily due to the difference between nondiscrimination and pursuing an equity goal: Not discriminating does not mean that a more-disadvantaged person has fewer barriers to use than a less-disadvantaged person. General language that use phrases such as "for all" do not address the different ways in which different population groups benefit from bike share and the strategies necessary to bridge those differences and ensure everyone does benefit. Most statements that had "for all” or references to "all backgrounds," "all cultures,” or "all social statuses” also lacked specificity about any particular groups.

System size appeared to have some influence on how extensive an equity statement was. Two of the three extensive statements or policies were from large systems. This made sense considering cities with large systems had, on average, a people of color share of the population that was nearly 10 percentage points higher than cities with mid-size systems and 14 percentage points higher than small-system cities. Additionally, the two large systems that provided extensive statements were in cities with the highest proportion of people of color population among large government-run systems in our sample. Smaller systems were the least likely to have provided us with an equity statement or policy; only 1 system provided one. With all systems, not having an equity policy did not necessarily mean they did not incorporate equity in some way in their system.

The most common themes across the provided equity statements were access and affordability. Access can mean many different things, and no system directly connected relevant policies with how they impacted access. Access can refer to density of stations, coverage, ability accommodations and payment systems, and we had to infer their meanings of access in later sections such as in station siting and fee structures. Where affordability was mentioned in an equity statement or policy, systems typically also referred to low-income populations, but none mentioned minority populations. As respondents provided more detail with later questions, it was clear that many, but not a majority of, bike share systems do have goals or strategies to target populations based on their race/ethnicity even if that was not apparent in their initial statements.

\subsection{METRICS AND DATA COLLECTION}

As might be expected, the share of systems that had a defined metric relating to equity and bike share (23\%) was similar to those that had an equity statement or policy (Table 2). As with an equity statement, specificity helps to ensure that goals are achieved. However, few of the systems surveyed offered clear metrics to rate success in achieving equity statement goals. When systems did have clear metrics, they typically referred to collecting demographic data or they specified race, income, gender, age, educational attainment, and location. Most systems alluded to general demographic information or just race, income, and location, and typically did not tie these back to their equity goals. Only two systems specified 
gender as something they wanted to measure, and a different system was the only one to specify wanting to measure educational attainment. Four of the systems had goals to ensure a certain percentage of stations were near target populations, typically low-income populations. The system with the most specific set of metrics focused specifically on its equity program, tracking how many trips equity program participants took and monitoring the overage charges they accrued. One of the two systems looking to measure the gender of riders had specific targets for the share of subsidized memberships held by women and the share of women among all bike share members.

Among 21 responding organizations that included details about equity metrics, nearly all wanted to collect data to understand who their users were, generally through user surveys of some type. However, the timing of the surveys, how often they were done, who was targeted for surveys, and how they were conducted varied substantially. For example, it was unclear which riders were targeted for surveys for most systems; four systems specified they were surveying only members, but one of them said they also do surveys for walk-up users. Several of the respondents said their data collection efforts are still in development, being redone, or dependent upon securing funding. Five of the systems specified they were using the data they collected to measure progress toward equity goals.

\subsection{EQUITY CONSIDERATIONS}

Among aspects of system design and operation, equity considerations appear most likely to influence station siting and fee structure and payment systems, followed by promotion, outreach and marketing (Figure 2). Few systems said that equity considerations had no role in their bike share system, particularly on the aspects that directly face potential users. Only $11 \%$ did not consider equity in station siting or fee and payment systems. About a quarter of systems said that equity was not considered in their system's operations (27\%) or data collection (25\%). A similarly small number of systems responded they did not know or the particular aspect was not applicable to their system. This was likely an effect of having the survey answered by only one person in the organization. The stated effect of equity on these aspects of bike share did vary by system size. In all five areas, large systems were significantly more likely to have considered equity than the smaller systems (one-way ANOVA, $\alpha=0.05$ ). We did not see significant differences between the smallest and mid-size systems. 


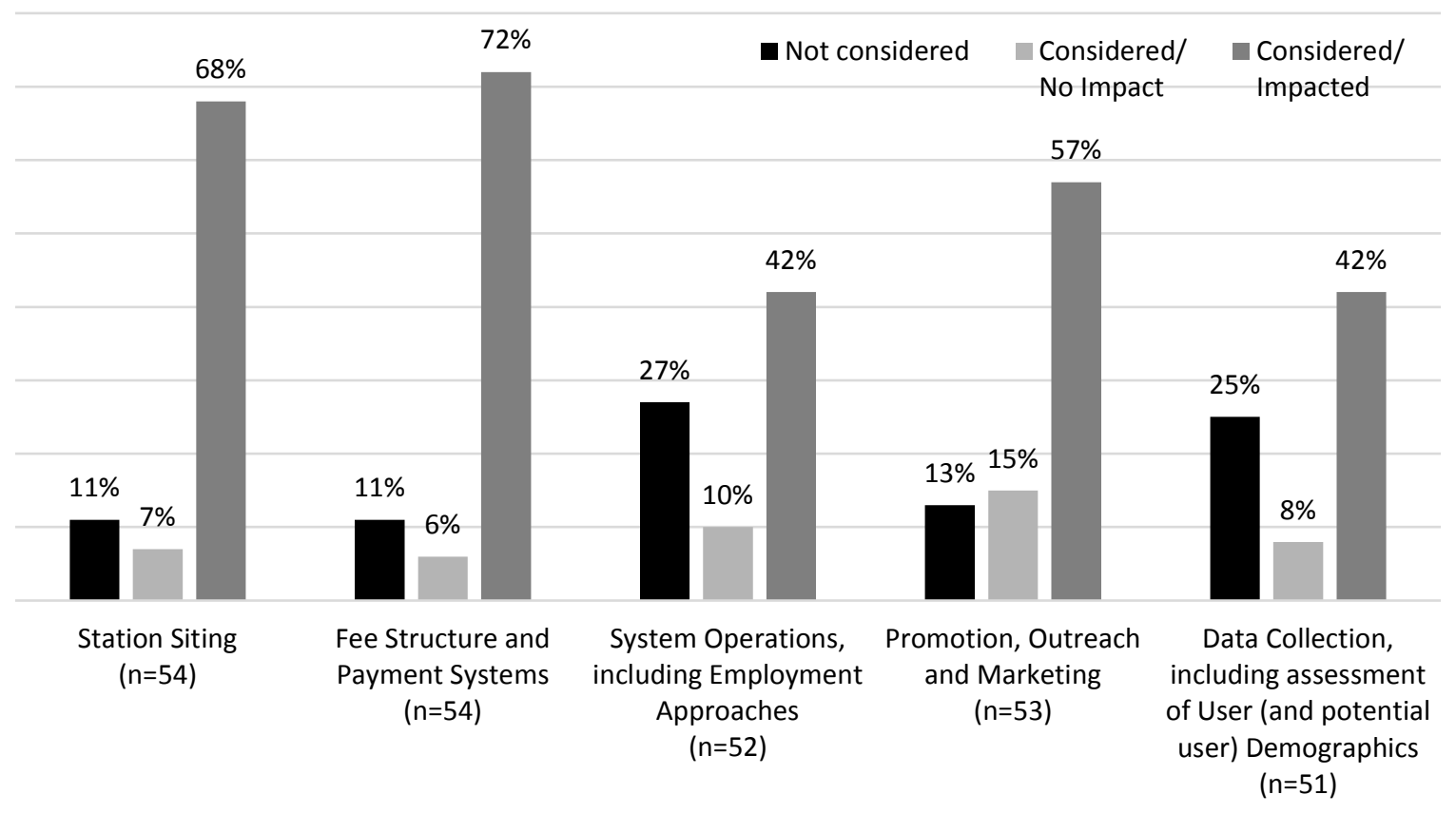

Note: Percentages do not total 100\% due to "Don’t Know/NA” responses. Possible survey responses were: Not considered; considered, no impact; considered, minor role; considered, considerable role; considerations primary driver. We combined minor role, considerable role, and primary driver into the Considered/impacted category here.

Figure 2 How is equity considered in specific areas?

The share of systems indicating that equity was a consideration in these five aspects of their systems was generally much higher than the share of systems that have adopted an equity statement (23\%). This implies that an equity statement is not necessary for equity to influence actions. However, those reporting having an equity statement also had higher mean responses to specific equity consideration and impact in all surveyed areas: station siting, fee structures, operations, promotion, and data collection. The differences in fee structure, promotion, and data collection decisions were significant (one-way ANOVA, $\alpha=0.05$ ). This indicates that having a defined equity statement, while not necessary, can help systems give greater consideration to equity when making bike share system decisions. Figure 3 demonstrates that bike share systems with equity statements were more likely to consider equity in more elements of their system operations. 


\section{Having an Equity Statement Affected Consideration and Impact of Equity on Bike Share System Decisions}

\section{Without Equity Statement With Equity Statement}
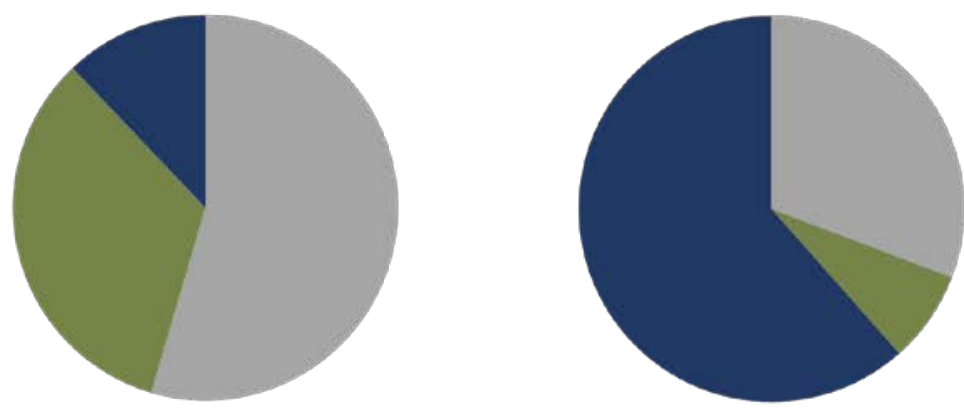

0 Elements

1-2 Elements

3-5 Elements

Note: Number of key areas where equity had "considerable" or "primary" role. Those responding "Other" to whether they had an equity statement were excluded.

Figure 3 Number of elements in which equity is considered, by whether the bike share system has an equity statement

The sections below describe some of the examples of how systems incorporated equity into these aspects of their systems, based on answers to the open-ended questions on the survey.

\subsubsection{Station siting}

Station siting was one of the most common ways systems incorporated equity. Figure 2 provides selected examples by level of equity consideration and whether that consideration impacted the structure of that piece of their system. Accessibility was a prominent feature in station siting. One way that systems addressed access was to promote transit connectivity and place stations at public housing complexes. Others featured places with connections to jobs, commercial areas, and recreation as important areas to locate stations for their targeted equity populations. Some system respondents referred to a goal of large coverage areas and having walkable distances between stations. Three of the 14 large systems stated they included quotas on siting stations in low-income and minority neighborhoods.

Table 3 provides quotes from system respondents on the role of equity in their station siting. This table shows how systems saw the role of equity and the range of actions that occur with how important equity was to the process. As can be seen, there was no real relationship between the actions systems said they took on equity in station siting and the role equity played in the process. 
Table 3 Examples of equity consideration in station siting

\begin{tabular}{|c|c|c|}
\hline Category & $\mathbf{n}$ & Specific Examples \\
\hline $\begin{array}{l}\text { Considered but } \\
\text { did not change } \\
\text { outcome }\end{array}$ & 4 & $\begin{array}{l}\text { "Stations were placed in low-income areas that fit within the overall } \\
\text { connectivity of the system.” } \\
\text { "Our smaller bike share system and the design of our downtown doesn't } \\
\text { afford us too many options to reach the equity population. That said we } \\
\text { ensured we addressed new multi-family equity housing. The density and } \\
\text { location of the complex meant it would have been serviced regardless of } \\
\text { the equity consideration.” }\end{array}$ \\
\hline Minor Role & 19 & $\begin{array}{l}\text { "We looked at addressing equity in siting by co-locating stations at transit } \\
\text { hubs to serve low income residents as last mile connections and siting } \\
\text { stations at partnering affordable housing communities.” } \\
\text { "We took a look at age. We placed one of our stations with a trike at the } \\
\text { community center that has a senior focus to ensure that seniors could } \\
\text { utilize the bikes." } \\
\text { "Only if the funding source required equity considerations" } \\
\text { "[W]e placed a few stations in 'underserved areas"” } \\
\text { "Evaluated based on MPO [...] definition which looks at ethnicity, income, } \\
\text { car ownership, language spoken, seniors as \% of population, children as } \\
\text { \% of population, etc." }\end{array}$ \\
\hline $\begin{array}{l}\text { Considerable } \\
\text { Role }\end{array}$ & 17 & $\begin{array}{l}\text { "[System expansion has] committed a significant percentage of stations to } \\
\text { [specific] neighborhoods, bus stops, and commercial areas frequented by } \\
\text { [the] Latino community.” } \\
\text { "Over } 80 \% \text { of the [...] stations we will add this year will be in low-income } \\
\text { neighborhoods.” } \\
\text { "City made sure that the vendor placed at least } 20 \% \text { of their system in } \\
\text { regionally defined [equity areas]" } \\
\text { "[W]e intentionally sited stations near low income housing” } \\
\text { "We identified areas made up of specific demographics that are typically } \\
\text { underserved by bike share programs. Once those areas were identified, } \\
\text { we located nearby bus and transit stops along with parks and community } \\
\text { centers. Bike stations were then permit[te]d and installed in those } \\
\text { areas." }\end{array}$ \\
\hline Primary Driver & 1 & $\begin{array}{l}\text { "We've sited stations for reason of equity in areas where we don't see } \\
\text { adequate demand and otherwise would not have placed them there" }\end{array}$ \\
\hline
\end{tabular}

Note: Minor role, considerable role, and primary driver refer to the considered/impacted category in

Figure 2. Considered but did not change outcome refers to the considered/not impacted category.

\subsubsection{Fee Structure and Payment Systems}

As with station siting, many more systems (40) said they incorporated equity in how they set up their fee structure and payment systems than had provided equity statements or policies (13). Fee structure strategies for equity primarily fell within three categories: cost, discounts, and payment systems. Incorporating any of the three could be seen as increasing access to the system by removing barriers to use. 


\subsection{COST}

For cost, some systems started off with pricing that they deemed attractive for a broad range of users. Others reevaluated their pricing and lowered their pass costs across the board. Bank holds that acted as deposits for bikes were an equity barrier some systems found in their pricing and either eliminated them or reduced the cost. To address some cost concerns, seven systems opted to offer more variation in their membership options, introducing monthly and weekly options, for instance, or free membership with a pay-per-ride structure. Some changed their annual memberships to be paid monthly to help those who found a large up-front payment too much of a barrier. One system prioritized simplifying the fee structure and making it easier to understand. Additionally, one system used the contract bid process to encourage applicant operators to provide "innovative fee structures."

\subsection{DISCOUNTS}

Fourteen responding organizations offered free or discounted memberships. Free memberships usually consisted of a $\$ 0$ registration or membership, with per-ride charges (in some cases tied to the cost of a transit fare) being the only cost users would have to pay. One of the four systems that reported free membership had a grant-funded zero-cost program for its target equity population. Systems administering discounted passes often qualified a person if they were receiving some other sort of public assistance or met certain income thresholds. Thus, they were often tied to low-income populations, but not necessarily targeting any racial or ethnic groups. The discounts on memberships can vary considerably; for example, one system reported they offered \$5 annual memberships and another offered \$5 monthly passes. At least two of the systems reported they administered their subsidized passes through community organizations.

\subsection{PAYMENT SYSTEMS}

Serving unbanked populations was a barrier that 13 systems specifically reported they were planning to or had tried to address. Most of those respondents were working to offer cash payment options, typically through commercial establishments such as grocery or convenience stores. One system reported it was accepting cash payments through its library system. Some systems addressed cash payment needs by allowing accepting pre-paid credit/debit cards and gift cards. One respondent stated their unbanked-user strategy is looking to also incorporate homeless populations.

\subsubsection{System Operations}

In systems where equity was incorporated into operations, six had policies of paying a living wage and hiring locally. Five systems partnered with local workforce development organizations or public housing to find potential hires. At least one system specifically hired people of the demographic they were targeting for their equity program as advocacy staff to help with outreach. 
For overall operations, many stated that the way their operations were organized made it difficult to implement equity considerations in their operations. This happened with systems where cities contracted with an operator, there was a multijurisdictional arrangement, or where particular municipal rules limited flexibility. However, two systems either used the bidding process to choose an operator that identified equity considerations in hiring that the system was looking for, or swayed the selected operator to incorporate equity considerations.

\subsubsection{Promotion, Outreach, and Marketing}

As with many of the other equity considerations made by the respondent systems, promotional activities done for equity purposes were quite varied. However, there were some common elements among systems. Eleven respondents had promotional materials translated into at least Spanish. Nine systems specifically targeted low-income communities. Five specifically targeted people of color populations by incorporating images of people of color in advertising materials or conducting outreach in specific neighborhoods. Eight stated their promotional activities were either inclusive or representative of the community. Three systems stated they had or are trying to form partnerships with organizations ranging from public housing authorities to neighborhood organizations active in the communities they are trying to target in order to get help with outreach. Another three systems stated they are promoting bike share at community events in targeted communities.

\subsection{EQUITY BARRIERS}

\subsubsection{Perceived barriers for targeted equity users}

Our survey included two questions (both open-ended) on barriers as seen from the operator perspective: one relating to users and one relating to their organization. Forty-four systems shared what they perceived to be the key barriers for targeted equity users. Generally, these barriers fell into the categories of pricing and payment systems, access, perceptions, and awareness and understanding of how the system works.

Twenty-two of the 44 systems stated that a key barrier was related to the price or payment system of their bike share (see Figure 4). Of these 22 systems, 15 stated that cost to use the system was a key barrier and 15 also stated those without credit/debit cards would face large barriers to use the system. Most of those systems have made some effort to address those barriers through cash payments, pre-paid card acceptance, and discounted passes. Five systems recognized the difficulty they will have in attracting targeted equity populations to bike share with either cash payment options or subsidized passes and that they really need both to be successful. Relatedly, many also recognized the issues of access to smart phones and the internet for low-income and minority populations. 


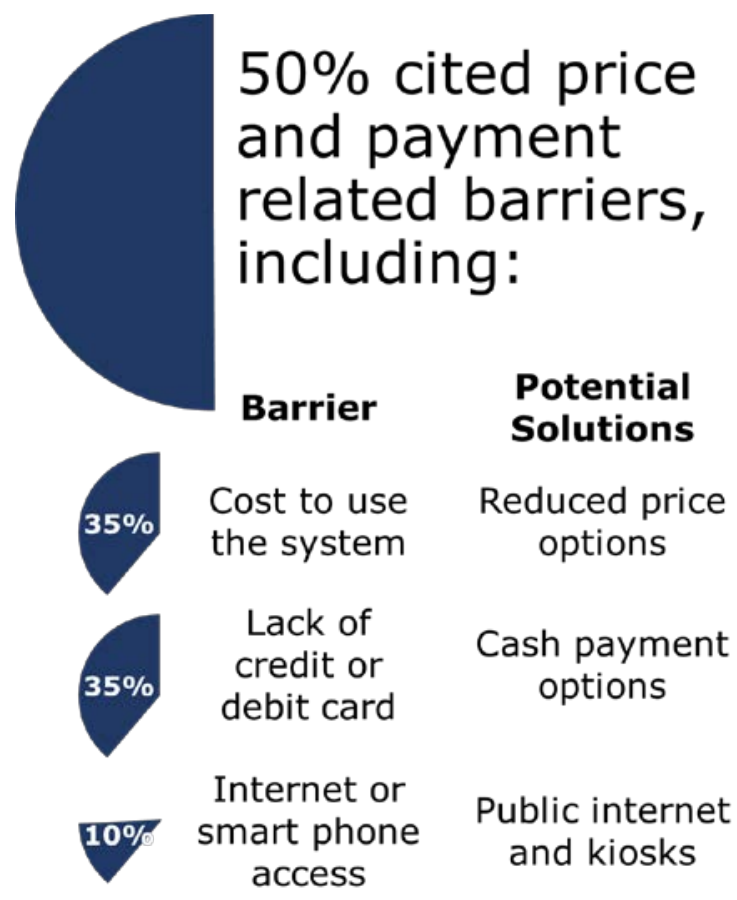

Figure 4 Operator-identified price and payment barriers for target populations, and potential solutions

Various aspects of access to stations were cited as a key barrier to underserved users by 19 systems (see Figure 5). Bike infrastructure was cited as a barrier by six systems while lack of transit connections was cited by one system. One system said, "No one advocates or values bike infrastructure in poorer areas of town, so they don't get investment” for why they feel lack of bike infrastructure was a barrier to their potential users. Getting to and safely using the bike was only part of the access problem. Nearly all systems that listed access as a problem stated their system had not expanded to areas where targeted equity users could use the system, or their station network was not dense enough in low-income and minority neighborhoods for it to be useful. Similarly, several systems saw limited ability to place stations in underserved areas because of the lack of residential density in such neighborhoods or said that target populations lived in neighborhoods too far from the existing bike share network. 


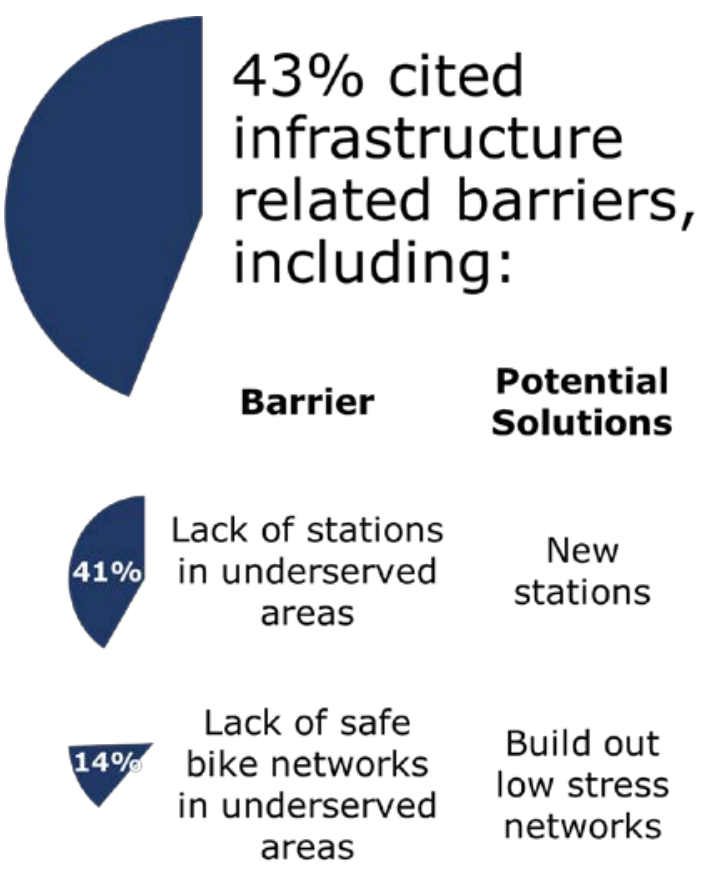

Figure 5 Operator-identified infrastructure-related barriers for target populations, and potential solutions

Eleven systems saw perceptions of bike share as a significant barrier (see Figure 6). Most of the perceived barriers revolved around bicycling in general. For example, systems noted that the people their equity programs target see bicycling as something that is "not for them," and more for the "epic outdoor folks" or "people in spandex." Three systems saw perceptions of safety while riding a bike as a significant barrier. Safety concerns were raised for both riding and potential crime such as this from one respondent,

"[T] he downtown area, which is where the initial bike share system is being launched, is evolving with some particularly vibrant areas; however, there are many other parts of downtown that may be perceived as unsafe. This may inhibit use of the system by younger and older populations as well as women, if they don't feel safe walking to/from bike share stations."

Some systems also believe their target equity populations are unlikely to join because of the stigma associated with bicycling, particularly around the status symbol of owning a car versus riding a bike.

"We've struggled to get people on bikes in some communities. It's been less about cost, credit cards etc. and more an issue of cultural attitudes about biking. We've installed bike stations and offered free memberships but uptake has been low. In some communities bike sharing as it's typically practiced isn't appealing and potential users may be better served by some other form of access to bikes such as long term loan programs or programs that enable them to earn or get financing for a bike of their own." 
Perceptions that bike share contributes to gentrification were cited as a barrier by one system.

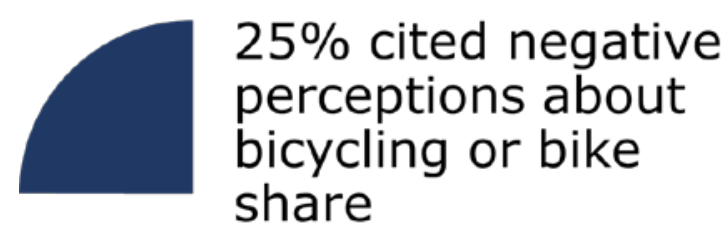

Figure 6 Operator-identified perceptions of bike share can be a barrier

How much potential users know about and are aware of bike share and how to use it were reasons 14 systems cited as barriers for bike share uptake by their target equity populations (see Figure 7). Three systems felt their target demographics were unaware of the system. Another three recognized that the lack of multilingual instructions at stations is a large barrier to some target populations. However, most in this category (10 of 14) cited confusing language in their instructions and fee structures as well as ineffective or poor communication and educational outreach limiting the uptake of bike share by populations they are targeting for their equity programming. Only one of those systems stated that it was trying to make the language of its fee structure clear and understandable. Even though most systems appear to have some form of communication and outreach program, the number of systems that see this as a barrier suggests many still feel they have much more room to improve.

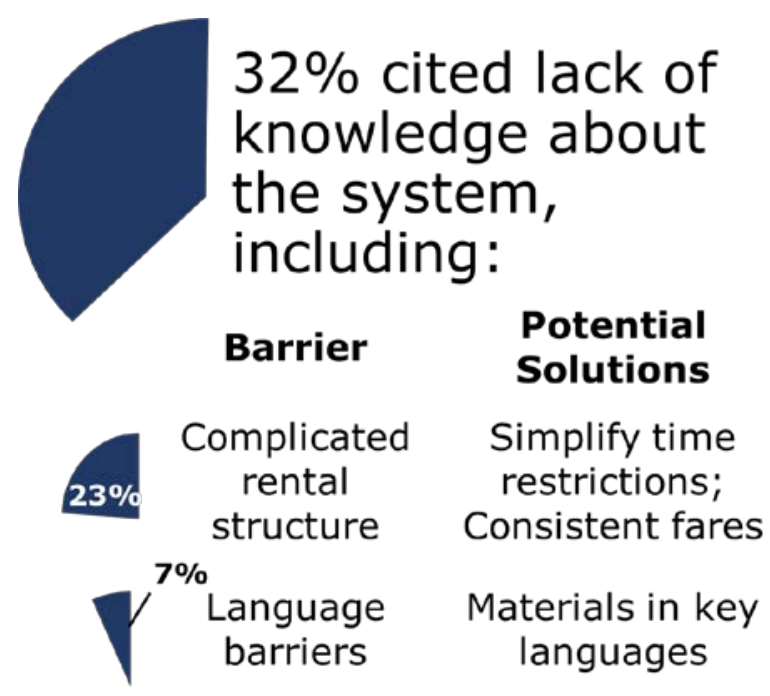

Figure 7 Operator-identified knowledge barriers for target populations, and potential solutions

\subsubsection{Barriers for the organization}

A large majority of our responding bike share systems (24/37 responses) saw their operational funding and staff levels as the biggest barrier to succeeding in their equity strategies. Several systems stated they had such small staffs, it was impossible for them to focus on equity strategies. But even the large systems had difficulty finding staff time. 
Second to funding and staff levels was the ability to convince necessary stakeholders such as city governments and decision-makers, funding partners, operators, and the general population that pursuing equity strategies was a worthwhile effort. One system's community was very affluent with a very small targeted equity population, which made it difficult to convince the community and decision-makers that it was worth the time and money to serve the targeted equity populations. Another system indicated that the operator could be a barrier; given its objective of running a business, opening low-use stations in neighborhoods targeted for equity programming could be a tough sell. However, this points to what is perhaps more of a funding barrier, as many systems rely on private operators, with minimal or no public funding for operations.

Other barriers were mentioned by fewer than five of the systems. These included difficulties developing effective education and marketing materials and outreach programs, organizational partnerships (including finding the groups that have the best connections to the target populations), the inability to accept cash, the risk of losing bikes without having a credit card on file, and organizational (provider) limitations.

\subsection{FUTURE PLANS}

Those who provided us with statements on their future plans were almost entirely systems that were just becoming operational, starting their equity programming, or actively looking to expand. As such, many of the plans follow the path of those who are currently operating fullscale equity programs, such as discounted passes, cash payment systems, hiring community advocates, expanding stations into low-income and minority neighborhoods, and making their promotional materials more representative of the populations they are targeting. Some stated they are seeking the funding to have an equity program. One is exploring opportunities to make bike share more accessible to users of all abilities, a feature only once mentioned as currently existing.

We noted that pre-launch systems on average reported higher levels of equity consideration and impact in all aspects of planning and operations. This is consistent with the notion that equity is becoming a more integral part of U.S. bike share systems. Alternatively, it is also consistent with equity aspirations that may not be attainable due to resource limits and other barriers that arise after launch.

\subsection{STRENGTHS AND LIMITATIONS}

Our survey received a high response rate (75\%), and many respondents provided a good amount of information in the open-ended questions. However, lack of detail in some responses does not necessarily reflect a lack of equity consideration. Conducting interviews with system owners/operators would allow the ability to ask clarifying questions to better understand how systems are defining and addressing equity, and how they reached these decisions. Having more than a single respondent from each system would also be useful in gathering those additional data. Finally, it is worth reiterating that a survey of operators may not always accurately reflect the perceptions and opinions of the targeted equity populations. 


\subsection{CONCLUSIONS}

The number of bike share systems in the U.S. has grown rapidly. As with any new service or technology, there have been growing pains. Several systems have been criticized for the lack of ethnic and/or income diversity among users, and overall, systems appear to be responding to these concerns. We found that $23 \%$ of surveyed systems have adopted an equity statement or policy, and $7 \%$ are in the process of developing one. Moreover, for a majority of surveyed systems, equity had influenced several aspects of their planning and operations. In particular, $68 \%$ of the systems stated that equity influenced their station siting decisions. This figure is notably higher than surveys conducted a few years ago of 35\% (18) and 43\% (8). A similar share (72\%) indicated that equity influenced fare structure and/or payment systems. Pricing, payment systems, and access to stations were cited by the respondents as the largest barriers to having more diverse populations use bike share. Over half (57\%) of the systems considered equity in their promotion, outreach, and marketing. This could help address the third-most cited barrier to having more diverse people use bike share - individual perceptions of bike share. Respondents felt that many people of color and lower income groups have negative perceptions of bicycling or bike sharing, or at least perceptions that bicycling or bike share was "not for them."

While many more systems indicated that equity influenced their decisions than had official equity statements or policies, we did find that systems with such policies were more likely to have taken actions related to equity. Therefore, there is likely value in having systems adopt explicit equity policy statements. For example, such statements may help maintain equity as a priority over time, particularly as leadership changes. We did, however, note that many of the equity statements, and particularly the metrics used to measure equity, lacked specifics. As systems mature, having specific metrics to gauge progress is important if equity is an actual goal. Similarly, the language used in equity statements can be key for focusing on outcomes. Language such as "for all” has implicit equity considerations, but it lacks the specificity that helps develop the metrics and programming necessary to ensure the system is actually "for all." For instance, being Black does not automatically mean being unable to afford the bikes, but it does relate to issues of historic and continuing racial segregation, what and where transportation investments are and have been made, and whom the investments benefit. At the same time, being low-income is a status shared by all racial/ethnic groups, but a geographically constrained area where most people have low incomes is also often a minority neighborhood. Thus it is critical to define the "who" in equity and the strategies necessary to achieve equity in the system with each group.

We found that large systems were more likely to have equity statements and to have considered equity in the major aspects of their systems, including station siting, fare structure and payment systems, operations, marketing/outreach, and data collection. There may be several (likely related) explanations for this. The survey respondents indicated that funding/staffing was their biggest barrier to addressing equity. Larger systems may have more financial and staff capacity to address equity concerns - and more bikes - thus likely making it easier to locate stations in low-income and minority neighborhoods. It is worth noting here that a system's financing model can play a major role in station siting. Systems that rely more on user- and ad revenues for 
operations may be reluctant to site stations in neighborhoods with high shares of lower-income households where the perception is that ridership will be low.

While this survey revealed the current level of action that bike share systems are taking to address equity, as well as many specific activities, it did not assess the effectiveness or outcomes of these efforts. The limited research that has been done finds mixed results (17). Given limited resources, providers need information on those efforts - particularly fare structures, payment systems, and marketing/outreach - that are most effective at improving the diversity of system users. In addition, if such efforts are successful, it would also be useful to assess what effects access and increased use have on targeted equity users. For example, a large body of literature links transportation access to positive economic outcomes, such as job placement and retention. Does bike share use have similar outcomes? Bicycling has also been linked to higher levels of physical activity and other health indicators. Does bike share improve these outcomes for lowerincome populations and people of color? Bike share operators could play a key role in facilitating research that answers these questions. 


\subsection{REFERENCES}

1. Fishman, E. Bikeshare: A Review of Recent Literature. Transport Reviews: A Transnational Trans-disciplinary Journal, Vol. 36, No. 1, 2016, pp. 92-113.

2. Transport Research International Documentation [TRID]. Search results Keyword="bike shar*" OR "bicycle shar*"; Subject Area="Pedestrians and Bicyclists"; Languages="English". Accessed on April 12, 2017. http://trid.trb.org.

3. Lewis, T. Has London’s Cycle Hire Scheme Been a Capital Idea? The Guardian, July 10, 2011. http://www.guardian.com/uk/bike-blog/2011/jul/10/Boris-Bikes-Hire-SchemeLondon?Commentpage-all. Accessed July 30, 2016.

4. Woodcock, J., M. Tainio, J. Cheshire, O. O’Brien, and A. Goodman. Health Effects of the London Bicycle Sharing System: Health Impact Modelling Study. British Medical Journal, Vol. 348, g425, 2014, pp. 1-14.

5. Shaheen, S. A., E. W. Martin, and A. P. Cohen. Public Bikesharing and Modal Shift Behavior: A Comparative Study of Early Bikesharing Systems in North America. International Journal of Transportation, Vol. 1, No. 1, 2013, pp. 35-54.

6. Buck, D., R. Buehler, P. Happ, B. Rawls, P. Chung, and N. Borecki. Are Bikeshare Users Different from Regular Cyclists? First Look at Short-Term Users, Annual Members, and Area Cyclists in the Washington, D.C., Region. Transportation Research Record: Journal of the Transportation Research Board, No. 2387, 2013, pp. 112-119.

7. Goodman, A. and J. Cheshire (2014). Inequalities in the London Bicycle Sharing System Revisited: Impacts of Extending the Scheme to Poorer Areas but Then Doubling Prices. Journal of Transport Geography, Vol. 41, 2014, pp. 272-279.

8. Shaheen, S., E. Martin, N. D. Chan, A. P. Cohen, and M. Pogodzinki. Public Bikesharing in North America During a Period of Rapid Expansion: Understanding Business Models, Industry Trends and User Impacts. San Jose, CA: Mineta Transportation Institute, 2014.

9. Hoe, N. and T. Kaloustian. Bike Sharing in Low-Income Communities: An Analysis of Focus Groups Findings. Temple University, 2014. http://b.3cdn.net/bikes/fc16c31cbff25139a1_3cm6bfs04.pdf. Accessed July 30, 2016.

10. Community Cycling Center. Understanding Barriers to Bicycling Project: Final Report, 2012. http://www.communitycyclingcenter.org/wpcontent/uploads/2012/07/Understanding-Barriers-Final-Report.pdf. Accessed July 30, 2016.

11. Smith, C.S., J-S. Oh, and C. Lei. Exploring the Equity Dimensions of US Bicycle Sharing Systems. TRCLC 14-01. Transportation Research Center for Livable Communities (TRCLC), 2015. http://www.wmich.edu/sites/default/files/attachments/u428/2015/TRCLC_RR_14_01.pdf . Accessed July 30, 2016.

12. Ursaki. J. and L. Aultman-Hall. Quantifying the Equity of Bikeshare Access in U.S. Cities, 16-0426. Presented at Transportation Research Board 95th Annual Meeting, Washington, D.C., 2016. 
13. Ogilvie, F. and A. Goodman. Inequalities in Usage of a Public Bicycle Sharing Scheme: Socio-Demographic Predictors of Uptake and Usage of the London (UK) Cycle Hire Scheme. Preventative Medicine, Vol. 55, No. 1, 2012, pp. 40-45.

14. Rixey, R. A. Station-Level Forecasting of Bikesharing Ridership. Transportation Research Record: Journal of the Transportation Research Board, No. 2387, 2013, pp. 46-55.

15. Stewart, S.K., D. C. Johnson, and W. P. Smith. Bringing Bike Share to a Low-Income Community: Lessons Learned Through Community Engagement. Minneapolis, MN: Preventing Chronic Disease, Centers for Disease Control and Prevention, 2011.

16. Carney, M. Bike-Sharing and the Unbanked: A Study of the Unbanked Population in Chicago and Best Practices for Their Inclusion in Bike-Sharing, 2012. http://chi.streetsblog.org/wpcontent/uploads/sites/4/2013/09/Bikeshare_Unbanked_Carney_Final.pdf. Accessed July 30, 2016.

17. Kodransky, M. and G. Lewenstein. Connecting Low-Income People to Opportunity with Shared Mobility: Final Report and Case Studies, 2014. https://www.livingcities.org/ resources/284-can-shared-mobility-help-low-income-people-access-opportunity. Accessed April 9, 2015.

18. Buck, D. Encouraging Equitable Access to Public Bikesharing Systems, 2012. https://bikepedantic.files.wordpress.com/2013/01/finalcapstonedbuckpdf.pdf. Accessed July 30, 2016.

19. Pedestrian and Bicycle Information Center. Bike Share Programs. http://www.pedbikeinfo.org/pdf/Programs_Promote_BikeSharePrograms_062116.pdf. Accessed July 30, 2016.

20. Martens, K., A. Golub, and G. Robinson. A Justice-Theoretic Approach to the Distribution of Transportation Benefits: Implications for Transportation Planning Practice in the United States. Transportation Research Part A: Policy and Practice, Vol. 46, No. 4, 2012, pp. 684-695. 
Transportation Research and Education Center

Portland State University

1900 S.W. Fourth Ave., Suite 175

Portland, OR 97201 